\title{
Green pigmentation on both deciduous and permanent dentition of a biliary atresia patient: A case report
}

\author{
Mi-Ri Kim¹, Sang-Ho Lee ${ }^{1,2}$, Nan-Young Lee ${ }^{1,2}$, Myeong-Kwan Jih¹, Young-Mi Yoon¹, and Yu-Jin Lim¹ \\ ${ }^{1}$ Department of Pediatric Dentistry, School of Dentistry, Chosun University, Gwangju 61452, Republic of Korea \\ ${ }^{2}$ Oral Biology Research Institute, Chosun University, Gwangju 61452, Republic of Korea \\ (Received Mar 30, 2017; Accepted May 2, 2017)
}

\begin{abstract}
Biliary atresia is a rare disease, and it is defined as partial or total absence of the biliary tract. If not treated, this disease may cause death within 5 years. Treatment methods for biliary atresia include conservative methods and surgical methods, such as a Kasai operation or/ and liver transplantation. Oral symptoms associated with biliary atresia are green pigmented teeth, enamel hypoplasia, rampant caries, enlargement of the pulp chamber and root canals, and delayed eruption of teeth. Among these symptoms, green pigmentation of teeth is the most significant and unesthetic complication affecting a child's social psychology. The majority of case reports about green pigmented teeth caused by biliary atresia showed that it affected the deciduous dentition rather than the permanent dentition. This case report describes the dental management of a patient with biliary atresia, who had undergone liver transplantation at age two years, and presented with green pigmentation in both deciduous and permanent dentition.
\end{abstract}

KEY WORDS: Biliary atresia, Deciduous dentition, Green pigmented teeth, Liver transplantation, Permanent dentition

\section{서 론}

담도폐쇄증은 출생 직후부터 3개월까지의 시기에 발생 하는 간장 외 담즙계의 부재, 파괴, 또는 폐쇄를 특징으로 하는 진행성 장애로 간경변, 섬유증, 그리고 담즙분비정지 를 초래한다. 이 질병은 대략 10,000 명당 1 명 정도의 비율 로 발생하며, 예후가 매우 불량해 치료하지 않은 경우 5년 이상 생존확률이 매우 낮은 것으로 알려져 있다. 담도폐쇄 증의 병인은 아직 명확히 밝혀지지 않았으나 감염, 면역, 유전, 형태발생적 요인 등이 원인으로 제시되고 있다. 임 상적으로 과빌리루빈혈증과 함께 폐색성 황달, 점토색변, 지방설사, 어두운 갈색뇨, 간비종대 등이 나타난다[1]. 치 료법으로는 고칼로리의 단백질 섭취, 지용성 비타민(A, D, $\mathrm{E}, \mathrm{K})$ 보충제 복용과 같은 보조적인 방법과 Kasai 수술(간 문장문합술), 간이식술 같은 외과적 방법이 있다. 최근 생 후 3개월 이내에 Kasai 수술을 통해 담즙흐름이 회복시켜 간기능을 최대한 오래 유지하고, 이후에도 황달이 계속되

*Corresponding author: Sang-Ho Lee

Department of pediatric dentistry, School of Dentistry, Chosun University, 309 Pilmun-daero, Dong-gu, Gwangju 61452, Republic of Korea Tel.: +82-62-220-3865, Fax: +82-62-225-8240

E-mail: shclee@chosun.ac.kr
거나 담도폐쇄증의 합병증이 지속될 경우 간이식을 시행 하는 순차적인 치료가 최적의 치료법으로 받아들여지고 있다. 불행히도 $80 \%$ 의 환아는 소아 간이식이 필요한 상황 을 맞이하게 되며, 간이식 수술은 평균적으로 만 1 2세경 에 시행되고 있다[2-4].

담도폐쇄증의 구강내 소견으로는 녹색으로 착색된 치아, 법랑질 형성부전, 심한 치아우식증, 유치의 확장된 치수강 과 치근관, 치아맹출지연 등이 있다. 이 중 녹색치아는 가 장 두드러진 특징으로, 치아발육과정 중에 발생된 과빌리 루빈혈증에 의해 이차적으로 발생하는 합병증이다 $[1,2,5]$. 뚜렷한 녹색착색이 발생하기 위해서는 혈중 빌리루빈 농 도가 $30 \mathrm{mg} / \mathrm{dL}$ 이상이 되어야 한다고 알려져 있다[5]. 빌 리루빈은 노란색을 띠는 반면, 빌리루빈의 산화물인 빌리 버딘(biliverdin)이 녹색을 띠기 때문에 녹색치아에 착색된 물질이 빌리버딘이라는 주장이 지배적이었다. 하지만 Watanabe 등[7]은 분광학적 분석을 통해 녹색치아에 침착 되어있는 물질이 빌리루빈임을 확인했다. 또한 녹색치아 절편의 조직학적 분석을 시행해 빌리루빈이 치아의 상아 질 내에 국한되어 존재하며, 성장선과 평행하게 침착되어 있음을 밝혔다.

담도폐쇄증 환자에서 발생한 녹색치아에 대한 보고는 대부분 유치열에 제한되어 있었다. 국내에서 보고된 3명의 담도폐쇄증 환아에서 발생한 녹색치아도 모두 유치열에서 
발생한 것이었다 $[8,9]$. 빌리루빈에 의한 녹색착색이 영구 치열에 비해 유치열에서 더 높은 확률로 발생하는 것인지, 아니면 종적연구의 부재로 인한 것인지에 대한 논의가 이 루어진 문헌은 없었다. 이론적으로, 영구치 발생 및 석회 화시기에 과빌리루빈혈증을 경험한다면 영구치에서도 충 분히 녹색착색이 발생할 가능성이 있다. 본 증례는 유치와 영구치 모두에서 녹색의 내인성 변색이 발생한 담도폐쇄 증 병력이 있는 환아에 대한 치과적 소견을 보고하는 바 이다.

\section{증례보고}

2014년 8월 만 5세 남아가 치아가 녹색으로 나왔는데 이를 치료할 수 있는지 상담받고 싶다는 주소로 조선대학 교치과병원 소아치과에 내원했다. 상기 환아는 담도폐쇄 증에 이환된 병력이 있어 이를 치료하기 위해 만 2세경에 $\mathrm{OO}$ 대학병원에서 간이식수술을 받은 경험이 있었고, 이후 지속적으로 면역억제제 및 항응고제를 복용하는 상태였다. 임상적으로 구강내 모든 유치열에서 녹색 변색이 관찰되 었고, 모든 상하악 유구치의 미약한 법랑질 형성부전이 나 타났다. 변색된 치아의 심미성을 개선하기 위해 지르코니 아 기성관 수복과 같은 유전치 심미수복 방법이 있지만, 유전치 치경부 및 전반적인 유구치 치관에서 변색이 관찰 되기 때문에 유전치부 수복만으로는 심미성 개선에 큰 도 움이 되지 않을 것이라 판단되었다. 다만, 유구치부의 법 랑질 저형성증으로 인해 우식이환율 높다 판단되어 예방 적 조치로 불소도포를 시행했다.

2년이 경과된 2016년 8월, 상기 환아가 하악 우측 유측 절치 동요를 주소로 본원에 재내원 했다. 재내원 당시 상 하악 제 1 대구치와 하악 중절치가 맹출 중이었으며, 맹출된 영구치 모두에서 녹색변색이 관찰되었다. 치아에 따라 녹 색착색이 관찰된 범위의 차이가 관찰되었는데, 상악 제1대 구치에서는 전체 치면에서 녹색착색이 나타난 반면 하악 중절치 및 제 1 대구치에서는 치경부를 제외한 치면에서 녹 색착색이 나타났다(Fig. 1). 환아의 병력을 고려해, 유치 발

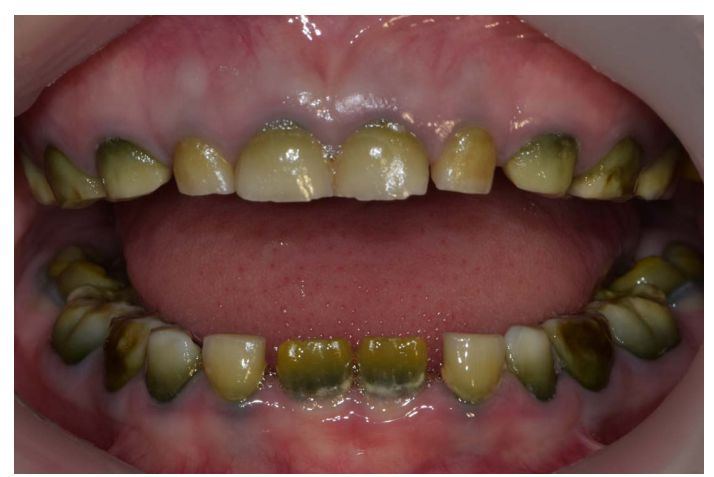

Fig. 1. Frontal view of green pigmented deciduous teeth and lower permanent central incisors. Green color was shown mainly on cervical part of crown in deciduous teeth. In lower permanent central incisors, green pigmentation was limited to incisal $1 / 2$ of crown and the color of cervical part was normal color of tooth without green intrinsic staining.

거 전 환아가 정기검진을 받고 있는 의과병원에 협진을 의 뢰했다. 그 결과, 유치 발치를 위해 예방적 항생제 투여가 필요하지 않고, 당시에는 항응고제 복용을 중단한 상태이 므로 과다출혈 발생 위험성이 낮다는 회신을 받았다. 이에 특별한 조치 없이 하악 우측 유측절치를 발거했다. 발거된 유측절치는 치경부에서 치근 중앙 $1 / 3$ 부위까지 뚜렷한 녹 색을 띄고 있으며 녹색은 법랑질과 인접한 상아질에 국한 되어 관찰되었다(Fig. 2). 또한 녹색착색은 치경부에서 치 근부 방향으로 갈수록 녹색이 짙어지는 경향성이 있었다.

상기 환아는 하악 우측 유측절치 발거 후 2주가 경과된 시점에 불소도포를 위해 재내원했다. 이 시기에는 구강내 로 하악 중절치가 완전히 맹출 했으며, 새로 맹출된 치경 부에서는 정상 치아색조가 관찰되었다. 새로 맹출된 치경 부 하악 우측 측절치 치관 $1 / 3$ 정도가 치은상방으로 맹출 했으며, 맹출된 부위 전반에 걸친 녹색착색이 관찰되었다 (Fig. 3). 녹색으로 착색된 치아의 형태적 이상 여부를 방 사선적으로 확인하기 위해 파노라마 방사선 사진을 촬영 하였으나 특이소견은 관찰되지 않았다(Fig. 4). 해당 내원 일에 치면세마 및 불소도포를 시행했다.

2017년 2월 환아가 정기검진을 위해 내원했으며, 임상검

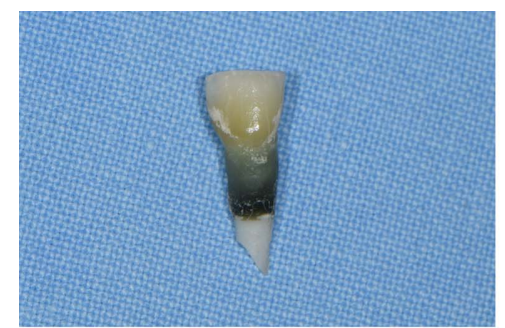

A

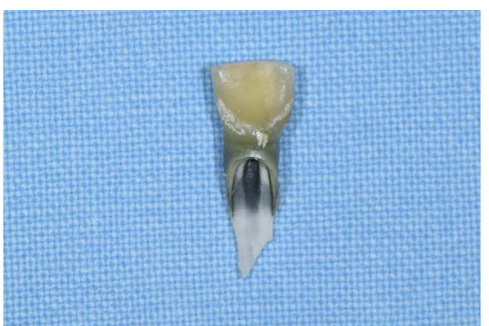

B

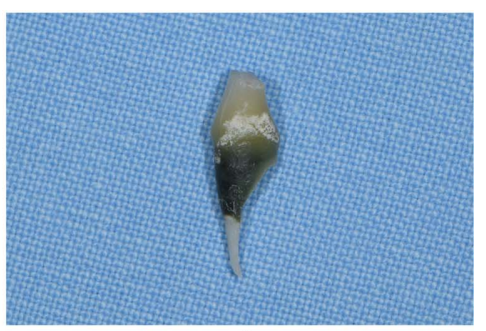

C

Fig. 2. Extracted green pigmented right lower primary lateral incisor. Significant green color is presented on cervical portion of crown and cervical 2/3 of root. (A) a labial view, (B) a lingual view, and (C) a lateral view of the tooth. 


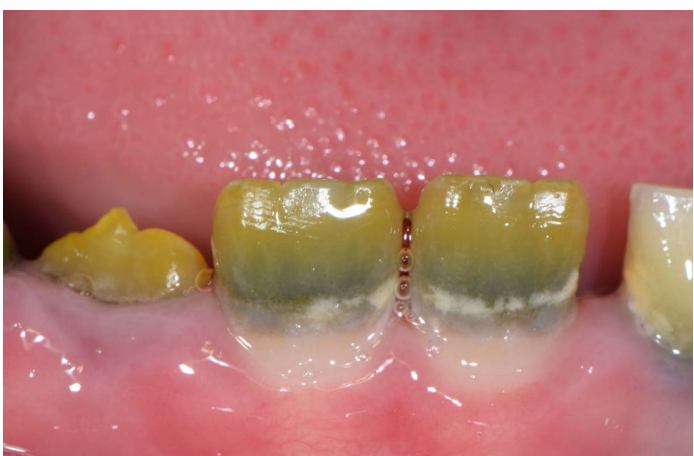

Fig. 3. Intra-oral photographs taken at two weeks after the extraction of right lower primary incisor. Green shade was also shown on the newly erupting right permanent lateral incisor.

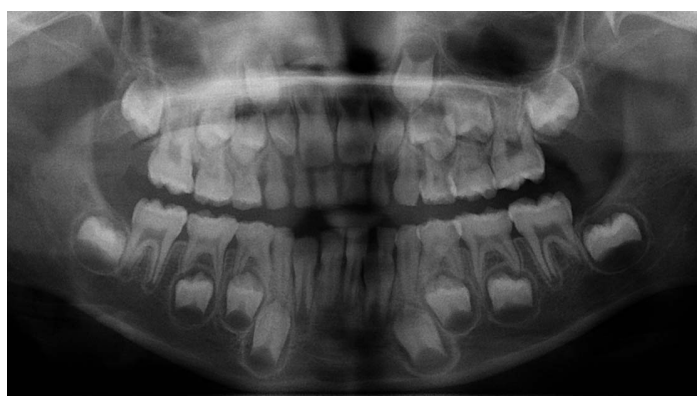

Fig. 4. Panoramic radiograph of the patient. Radiologically, there was nothing significant to report about the green teeth.

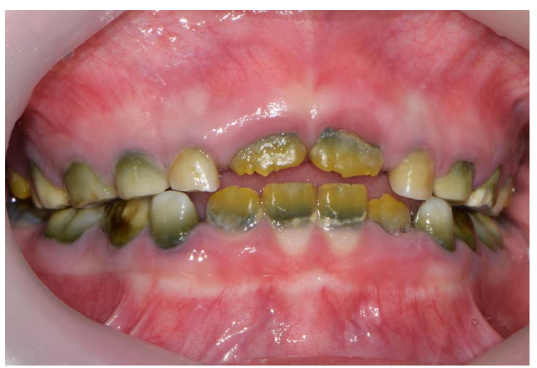

A

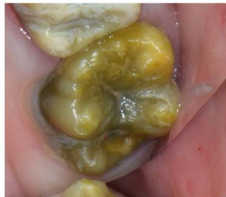

C

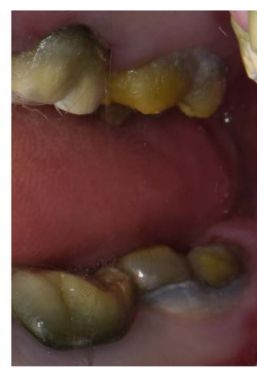

B

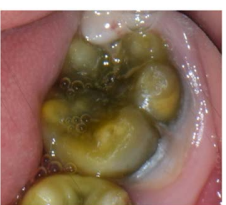

D
Fig. 5. Intra-oral photos after the dental restorative treatment. (A) a frontal view. At that time, upper central incisors were newly erupting, which had green pigmentation also. (B) buccal view of left first molars, (C) occlusal view of left upper first molar, and (D) occlusal view of left lower first molar. In first molars, green staining was shown on occlusal $1 / 2$ of the crowns, while the color of cervical part of crown was normal.

사 결과 상악 좌측 제 1 유구치의 교합면 치아우식증으로 진단되었다. 치과적 수복치료가 필요하다는 판단 하에 치 료를 시행하기 전 의과적 자문을 구했다. 그 결과 수복치
료 전에 예방적 항생제 복용 등의 조치가 필요하지 않다 는 답변을 받았고, 따라서 사전조치 없이 상악 좌측 제 1 유 구치 복합레진수복 및 상악 양측 제1대구치 치면열구전색 술을 시행했다. 치료 후 촬영한 환아의 구내 임상사진 (Fig. 5)을 살펴보면, 새롭게 상악 양측 중절치가 맹출 되었 음을 확인할 수 있으며, 맹출된 치관의 절단측 $1 / 3$ 부위에 서 전반적인 명확한 녹색착색이 관찰되었다. 상악 제 1 대구 치는 교합측 및 협설측 모두에서 전반적 녹색착색이 관찰 되었다. 반면, 하악 제1대구치 치관의 교합면 전체 및 치 관의 교합측 $1 / 2$ 부위까지 녹색착색이 관찰되어 치경부측 에서는 정상 치아색조를 관찰할 수 있었다.

\section{고 찰}

담도폐쇄증 환자에서 나타나는 치아의 내인성 녹색변색 은 과빌리루빈혈증 발생기간과 밀접한 관계가 있으며, 과 빌리루빈혈증이 치료된 이후 형성된 치아구조의 색상은 정상이다. 유치열의 석회화는 태생 4-6개월 유전치부를 시 작으로 생후 11 개월경 유구치부에서 마무리된다. 영구치 열의 경우 제 3 대구치를 제외하면 출생 직후부터 만 8세까 지 석회화가 이루어진다[10]. 담도폐쇄증이 출생 후 3 개월 이내에 특이적으로 발병하는 질환이기 때문에 태생 4-6개 월부터 석회화가 시작되는 유치열에서 녹색착색이 나타나 는 것이 일반적이다. 하지만 이보다 더 늦은 시기에 석회 화가 시작되는 영구치열의 경우 환자의 치료시기에 따라 녹색착색이 이환되지 않을 가능성이 있다. 이러한 이유로 담도폐쇄증에 대한 대다수의 증례보고가 유치열에 한정되 는 것으로 생각된다. 본 증례에서 환아의 간이식수술 시기 는 약 만 2 세경으로 이 때문에 유치열 뿐만 아니라 출생 시기에 석회화가 시작되는 제1대구치 및 생후 3-4개월에 석회화가 시작되는 상악 중절치, 하악 중절치와 측절치에 녹색 착색이 나타났다. 하악 중절치와 제 1 대구치의 치경부 에서는 정상치아 색이 관찰되어 해당부위가 간이식 이후 에 발생되었음을 알 수 있었다. 미맹출 영구치의 대부분에 서도 착색이 존재할 것으로 예상된다. 반면, 만 2세 이후 에 석회화되는 상하악 제 2 소구치와 제 2 대구치에서는 녹색 착색이 관찰되지 않거나 발생하더라도 교두부위 일부에만 관찰될 것으로 생각된다. 또한 8-10세경에 석회화가 시작 되는 제3대구치에서는 법랑질의 녹색 착색이 관찰되지 않 을 것으로 기대된다.

내인성 치아변색의 치료방법으로는 콤포짓 크라운 또는 라미네이트 수복, 표백 화학물질을 이용한 치아미백, 또는 자외선을 이용해 빌리루빈 산물의 파괴와 침전이 촉진되 도록 하는 방법이 있다 $[6,8]$. 하지만 내인성 치아변색은 치아미백의 효과가 미미하고 성장 중인 환아에게 콤포짓 
크라운이나 라미네이트 수복은 시행되기 어려워 이러한 내인성 변색치아의 치료는 시행하지 않는 것이 일반적이 다. 이러한 이유로 영구치열에 녹색변색이 발생한 경우 장 기적으로 심각한 심미성 저해를 초래해 환자와 보호자에 게 정서적, 심리적으로 영향을 미칠 수밖에 없다.

녹색치아의 특별한 치료방법이 없는 만큼, 되도록 영구 치에서의 녹색변색 이환율을 감소시키기 위해 조기에 담 도폐쇄증 치료를 시행하는 것이 중요하다. 일반적으로 담 도폐쇄증 치료를 위해 생후 3 개월 이전에 Kasai 수술을 시 행하고, 이후 증상이 개선되지 않을 경우 간이식술을 시행 하며, 미국의 경우 평균적인 간이식술 시기는 만 1 2세경 이다[4]. 본 증례의 경우 만 2 세경에 간이식술이 시행되어 평균적인 수술시기에 해당되기는 하나 비교적 늦게 시행 되었음을 알 수 있으며, 이로 인해 영구치의 광범위한 녹 색변색이 관찰되는 것으로 여겨진다. 수술시기를 결정함 에 있어 환아의 보호자는 녹색치아 합병증 발생 가능성에 대해 고지받은 바가 없었으며, 유치열의 녹색변색이 발생 되었을 때에도 기존에 간이식 치료를 받은 병원으로부터 영구치열은 정상적인 색조의 치아가 맹출할 것이라는 잘 못된 정보를 듣고 본원에 내원했었다. 담도폐쇄증의 치료 시기를 결정함에 있어 소아외과 전문의는 영구치열의 석 회화시기가 출생 직후부터 만 8세까지 진행되므로 치료가 지연될수록 더 광범위한 녹색변색이 발생함을 사전에 숙 지하고 있어야 한다. 또한 환아의 보호자에게도 녹색치아 변색 합병증 발생 가능성에 대한 정확한 정보를 제공할 수 있어야 한다.

또한 앞서 언급한 것처럼 대부분의 담도폐쇄증 환아의 녹색치아는 법랑질 저형성증이 동반된다고 보고되고 있다. 법랑질 저형성증은 대사장애에 의한 결과로 녹색변색과 직접적인 연관성은 없는 것으로 알려져 있다. 녹색치아에 서의 저형성증은 과빌리루빈혈증 중 특이적으로 담도폐쇄 증 병력이 있는 환자에서 높은 유병율을 보이는데, 학자들 은 저형성증이 과빌리루빈혈증과 지용성 비타민의 흡수장 애로 인해 발생한다고 추측하고 있다[9]. 본 증례에서도 하악 중절치 치관 중앙 $1 / 3$ 부위 및 구치부 교두부를 중심 으로 법랑질 저형성증이 나타났다(Fig. 3 and 5). 법랑질 저형성증과 녹색착색 사이에 직접적인 관련은 없다고 하 지만, 가장 짙은 녹색착색이 발생한 부위에 법랑질 저형성 증이 나타난 것을 관찰할 수 있다. 이는 환아의 혈중 빌리 루빈농도가 가장 높은 시기에 지용성 비타민의 흡수장애 로 인한 대사장애가 발생하는 것으로 유추해볼 수 있다.

담도폐쇄증 환아는 대부분 다발성 우식증에 이환되는 경우가 많다. 이는 법랑질 저형성증 보다는 지연된 젖병의 사용, 다량의 당성분을 포함한 경구약물 복용이 더 큰 기 여요인인 것으로 보인다[2,9]. 다행스럽게도 본 증례의 환 아에서는 만 7세경에 하악 우측 제 1 유구치의 교합면 치아
우식증 소견이 관찰되었을 뿐, 다발성 우식증에 이환되지 는 않았다. 담도폐쇄증 환자의 치과치료 시에 법랑질 저형 성증 동반 가능성과 높은 다발성 치아우식증 이환 가능성 에 대해 인지하고, 정기검진 및 불소도포 등을 통한 우식 증 예방 및 치료에 주의를 기울여야 한다.

담도폐쇄증 환자에서 나타나는 또 다른 특징은 방사선 사진상에 유치의 확장된 치수강과 근관이 관찰된다는 점 이다. 이러한 특징은 비타민 $\mathrm{D}$ 결핍의 영향으로 인해 발 생된다고 알려져 있다. 하지만 본 증례의 파노라마 영상에 서는 이와 같은 특이사항이 관찰되지는 않았다.

녹색치아가 관찰되는 환자는 과빌리루빈혈증의 병력을 가지며, 간이식술을 경험했을 확률이 높다. 간이식술을 시 행한 환자는 치과치료 시 주의해야 할 사항들이 존재하며, 치과의사는 사전에 이를 숙지하고, 사전에 의과적 자문을 구해 필요한 조치를 취해야 한다. 장기 이식수술을 받은 환자의 치과적 관리는 이식 직후 시기, 이식 후 안정기, 만 성 거부반응기 단계로 나누어 고려해야 한다. 이식 후 3 개 월 이내인 이식 직후 시기는 수술 합병증과 급성 거부반 응 발생 위험이 높은 단계이므로 통상적인 치과치료를 시 행하지 않아야 한다. 다만, 응급 치과치료가 필요한 경우 의학적 자문을 구한 상태에서 가능한 한 비침습적으로 시 행해야 한다. 이식 후 안정기는 이식편이 치유되고 급성 거부반응이 조절되는 시기로 일반적으로 통상적 치과치료 가 시행 가능하다. 다만 치과치료로 인해 감염, 과도한 출 혈, 스테로이드로 인한 스트레스에 대한 부작용, 면역억제 제로 인한 고혈압 같은 합병증이 발생할 가능성이 존재한 다. 감염 발생을 예방하기 위해 감염 예방 표준주의지침을 준수하고, 필요한 경우 예방적 항생제를 투여해야 한다. 하지만 실제로 모든 이식 환자에 대해 예방적 항생제 투 여효과가 있는지에 대한 명확한 과학적 근거가 없으며, 오 히려 반복적인 예방적 항생제 투여가 구강 균주 분포에 영 향을 미칠 위험이 있다는 일부의 견해가 존재한다. 따라서 간이식 환자의 침습적 치과치료를 시행하기에 앞서 의학 적 자문을 통해 예방적 항생제 처방 필요성을 확인해야 한 다. 간이식 환자가 복용하는 항응고제로 인한 과도한 출혈 을 예방하기 위해 사전에 의과적 자문을 구해 항응고제 감 량 필요성을 결정해야 한다. 항응고 수준이 국제표준화 비 율(INR) 3.5 초과가 관찰되면 치과적 수술을 연기해야 한 다. 또한 수술 시 지혈제, 트롬빈, 스플린트 등을 구비해 발생 가능한 과다출혈에 대비해야 한다. 이식환자의의 스 테로이드 복용은 부신기능저하를 초래해 치과치료로 인한 스트레스에 대한 대처능력 저하로 급성 부신위기가 발생 할 수 있으므로 이를 예방하기 위해 스테로이드 추가투여 필요성을 확인해야 한다. 만약 치과치료 시 급성부신위기 가 발생하면 즉시 하이드로코디손 $100 \mathrm{mg}$ 을 정주 또는 근 주 후 병원으로 이송해야 한다. 이식환자가 복용하는 사이 
클로스포린의 부작용으로 고혈압이 발생할 수 있으므로 치과의사는 이에 대해 인식하고 치과치료 전 혈압을 측정 해 고혈압이 관찰될 시엔 의과적 자문을 구해야 한다. 만 성 거부반응기는 이식편에 대한 만성 거부반응이나 이식 편대숙주질병의 증상과 징후가 나타나는 상태를 뜻하며, 일반적으로 이 시기의 치과치료는 응급을 요하는 경우에 만 시행해야 한다[11].

본 증례의 환아는 간이식을 시행한지 약 3년이 경과된 이 식 후 안정기에 본원에 내원해 의과적 자문을 구한 후 적절 한 치과치료를 시행할 수 있었다. 당시 환아는 면역억제제 복용하는 상태였으나 의학적 협진의뢰결과 유치 발치, 치면 열구전색술, 복합레진수복 등의 치과치료 시 예방적 항생제 는 필요하지 않다는 답변을 받았다. 또한 치과치료가 시행된 당시에는 항응고제 복용 중단한 상태로 과다 출혈의 위험성 예상되지 않는다고 회신했다. 따라서 본 증례의 환아의 치과 치료를 위한 부가적인 사전조치는 시행하지 않았다.

더 나아가 간이식 환자의 치과검진 시 악안면부위 연조 직 검진이 동반되어야 하며, 이는 이들 환자에서 머리와 목 부분에 림프절병증, 구강 연조직에 림프종, 편평세포암 종, 카포시 육종과 같은 악성 종양 발생 가능성이 증가하 기 때문이다. 치과의사는 정기검진 시 이와 같은 증상이 발생하는지를 주의 깊게 관찰하고, 의문의 병소가 발견될 시엔 생검을 시행해야 한다[2]. 이러한 이유로 녹색치아를 가진 환자가 내원했을 때 단지 녹색치아에 대한 치과적 처 치에 머무르지 않고 정확한 병력을 확인해 환자에게 적절 한 치과적 대응을 하는 것이 필요할 것이다.

\section{Acknowledgements}

This study was supported by research fund from Chosun University Dental Hospital, 2017.

\section{Conflict of Interest}

The authors declare that they have no competing interests.

\section{ORCID}

Mi-Ri Kim

0000-0001-8730-467x

Sang-Ho Lee
Nan-Young Lee
Myeong-Kwan Jih
Young-Mi Yoon
Yu-Jin Lim

0000-0003-2513-6871

0000-0002-4738-9389

0000-0001-9579-076x

0000-0002-5592-1064

$0000-0002-9311-4714$

\section{References}

1. Shapiro BM, Gallagher FE, Needleman HL. Dental management of the patient with biliary atresia. Oral Surg Oral Med Oral Pathol Oral Radiol Endod 1975;40:742747. doi: 10.1016/0030-4220(75)90442-9.

2. Sheehy EC, Heaton N, Smith P, Roberts GJ. Dental management of children undergoing liver transplantation. Pediatric Dentistry 1999;21:272-280.

3. Sundaram SS, Mack CL, Feldman AG, Sokol RJ. Biliary atresia: indications and timing of liver transplantation and optimization of pre-transplant care. Liver Transplantation 2017;23:96-109. doi: 10.1002/lt.24640.

4. Wildhaber BE. Biliary atresia: 50 years after the first Kasai. ISRN Surgery 2012;2012. doi:10.5402/2012/132089.

5. Morisaki I, Abe K, Tong LS, Kato K, Sobue S. Dental findings of children with biliary atresia: report of seven cases. ASDC J Dent Child 1990;57:220-223.

6. Chambers CP, O'Morain D, Keightley A, Webury RR. A case report of green pigmentation in the permanent dentition. J Dent Child 2012;79:189-192.

7. Watanabe K, Shibata T, Kurosawa T, Morisaki I, Kinehara M, Igarashi S, Arisue M. Bilirubin pigmentation of human teeth caused by hyperbilirubinemia. J Oral Pathol Med 1999;28:128-130. doi: 10.1111/j.1600-0714.1999. tb02010.x.

8. Baik BJ, Yang YM, Lee SI, Kim JG. Dental management of the patient with biliary atresia: a case report. Korean Acad Pediatr Dent 2000;27:70-76.

9. Lee CH, Lee SD, Kim YJ, Kim JW, Hahn SH, Lee SH. Case report of the intrinsic stained teeth of patients with biliary atresia. Korean Acad Pediatr Dent 2004;32:400-405.

10. Rosenthal P, Ramos A, Mungo R. Management of children with hyperbilirubinemia and green teeth. J Pediatr 1986;108:103-105. doi: 10.1016/S0022-3476(86)80780-6.

11. Little JW, Falace DA, Miller CS, Rhodus NL. Dental Management of the Medically Compromised Patient. Seoul: Daehan Narae Publishing; 2015. p.335-356. 